\title{
Sutural loosening and skeletal flexibility during growth: determination of drop-like shapes in sea urchins
}

\author{
Amy S. Johnson ${ }^{1 *}$, Olaf Ellers ${ }^{2} \dagger$, Jim Lemire $^{1} \mathscr{I}$, Melissa $_{\text {Minor }}{ }^{1} \ddagger$ \\ and Holly A. Leddy ${ }^{1} \S$
}

${ }^{1}$ Biology Department, Bowdoin College, Brunswick, ME 04011, USA

${ }^{2}$ Section of Evolution and Ecology, Division of Biological Sciences, University of California, One Shields Avenue, Davis, CA 95616, USA

\begin{abstract}
The shape of sea urchins may be determined mechanically by patterns of force analogous to those that determine the shape of a water droplet. This mechanical analogy implies skeletal flexibility at the time of growth. Although comprised of many rigid calcite plates, sutural collagenous ligaments could confer such flexibility if the sutures between plates loosened and acted as joints at the time of growth. We present experimental evidence of such flexibility associated with weight gain and growth. Over 13-, 4-, and 2week periods, fed urchins (Strongylocentrotus droebachiensis) gained weight and developed looser sutures than unfed urchins that maintained or lost weight. Further, skeletons of fed urchins force-relaxed more than did those of unfed urchins and urchins with loose sutures force-relaxed more than those with tight sutures. Urchins (Strongylocentrotus franciscanus) fed for two and a half weeks, gained weight, also had looser skeletons and deposited calcite at sutural margins, whereas unfed ones did not. In field populations of $S$. droebachiensis the percentage having loose sutures varied with urchin diameter and reflected their size-specific growth rate. The association between feeding, weight gain, calcite deposition, force relaxation and sutural looseness supports the hypothesis that urchins deform flexibly while growing, thus determining their drop-like shapes.
\end{abstract}

Keywords: sea urchin; biomechanics; collagen; ligaments; growth; morphospace

\section{INTRODUCTION}

Thompson (1917) proposed that the shape of an urchin is determined by patterns of mechanical forces acting on its skeleton. His idea is based on an analogy with a liquid drop sitting on a solid surface. In a drop, forces due to pressure and surface tension determine the local radii of curvature of the surface. The analogous forces in urchins are due to coelomic pressure, podia and self-weight. Also essential to the analogy is that the skeletal surface of an urchin is flexible and thus able to conform freely to the pattern of forces imposed.

Thompson's original hypothesis has been examined in several papers. Some evidence supporting the theory has been presented (Dafni 1986); coelomic pressure has been measured (Ellers \& Telford 1992); and explicit mechanical models have generated shapes that approximate reasonably to the shapes of urchins (Baron 1991; Ellers 1993). Most recently, the developmental morphospace generated by Ellers' model has been reviewed with other morphospaces (Foote 1997; Stone 1997; McGhee 1998;

\footnotetext{
*Author for correspondence (ajohnson@bowdoin.edu).

$\uparrow$ Present address: Biology Department and Coastal Studies Center, Bowdoin College, Brunswick, ME 04011, USA.

If Present address: Graduate School of Oceanography, University of Rhode Island, Narragansett, RI 02882, USA.

\$ Present address: Stanford School of Medicine, MSOB 347, Stanford, CA 94305, USA.

$\int$ Present address: Orthopaedic Bioengineering Laboratory, Duke University, Duke, NC 27710, USA.
}

Eble 2001). If they represent underlying causes of form, such morphospaces could be used to analyse macroevolutionary trends. It is crucial to assess the validity of the underlying assumptions in morphospace models because the models will be interpreted to constrain or bias evolutionary trends. Thus, in this paper we are concerned with assessing the validity of one important assumption, namely the assumption of flexibility during growth.

Flexibility may seem unlikely since urchin skeletons are composed of rows of many calcium carbonate plates that are themselves quite rigid. The plates, however, meet at sutures, which are attached to each other in two ways. Firstly, calcite rods project from one plate into interlocking spaces on adjacent plates. Secondly, the plates are sewn together with collagenous sutural ligaments that pass through pores in the edges of the plates and wrap around struts called trabeculae located on adjacent plates. These sutural ligaments are sometimes responsible for all of the strength of the skeleton (Ellers et al. 1998). The sutures could act as flexible joints if the sutural gaps were sufficiently wide that the calcite projections did not interlock, thus leaving the ligaments as the principal determinants of sutural properties. In Thompson's hypothesis, that skeletal flexibility should be associated with growth.

Urchins increase in size by the addition of calcite to the surfaces and edges of plates and by the addition of new plates at the apex (Deutler 1926), but little evidence exists regarding changes at the sutures during growth. A narrowing of the sutural gaps was observed in Heliocidaris erythrogramma, which shrank under reduced rations 
(Constable 1993). Such shrinkage under reduced food availability has also been observed in Strongylocentrotus purpuratus (Ebert 1967) and in Diadema antillarum (Levitan 1991). Similarly, 23\% of bleached skeletons of urchins (S. purpuratus) fed seaweed ad libitum for one year had visible sutural gaps, whereas none of an unfed group showed gaps (Ellers et al. 1998). However, that study was not designed to test for an association between growth and sutural gapping. No data were kept on weight or diameter changes and no tests were done to measure the mechanical impact of the gaps. Furthermore, the 1 year period of that experiment suggests that the unfed urchins may have been in an unusual physiological condition.

In this paper we specifically test for an association between feeding, weight change, calcite deposition and sutural looseness. We present short-term experiments with relevant weight and sutural looseness measurements taken at the beginning and end of the experiments. We test whether sutural loosening is reflected in the overall mechanical properties of the skeleton by performing force relaxation tests and testing for an association with sutural looseness. We test whether looseness is associated with calcite deposition and hence growth. Finally, we test whether there is an association between size-specific growth rates and sutural looseness in field populations.

\section{MATERIAL AND METHODS}

\section{(a) Growth and sutural changes in}

\section{Strongylocentrotus droebachiensis}

For the 13-week growth experiment, 143 urchins ( $S$. droebachiensis), between $25 \mathrm{~mm}$ and $82 \mathrm{~mm}$ in diameter, were collected subtidally in June from a kelp bed near East Bailey Island, Maine. For four- and two-week growth experiments, 91 urchins, between $43 \mathrm{~mm}$ and $71 \mathrm{~mm}$ in diameter, were collected subtidally in February from a coralline algae-encrusted ledge (i.e. an urchin barren) near Metinic Island, Maine.

At the start of the 13- and 4-week experiments urchins were assigned at random either to a pre-experimental (initial) group, an unfed group or a group fed mussel flesh ad libitum. Urchins were maintained in 3801 seawater aquaria at $9^{\circ} \mathrm{C}$. The twoweek experiment was a continuation of the four-week experiment in which a random subset of the unfed group was fed mussel flesh ad libitum for an additional two weeks. Starting and ending wet weights $( \pm 0.1 \mathrm{~g})$ were obtained and at the end of the experiments, urchins were bleached and assayed to ascertain whether the bleached skeletons disarticulated into constituent plates under their own weight or whether they remained intact.

For the four- and two-week growth experiments, force relaxation tests were performed on urchin skeletons for all pre-experimental (initial) and experimental urchins. Prior to testing, spines were removed from the oral and aboral surfaces so that a force could be exerted directly onto the skeleton along that axis. Skeletons were compressed at $0.2 \mathrm{~mm} \mathrm{~s}^{-1}$ until a force of $15 \mathrm{~N}$ was reached and the subsequent decrease in force (force relaxation) was followed for $180 \mathrm{~s}$. The force signal (error $\pm 0.01 \mathrm{~N}$ ) was amplified and digitized (12 bit, $100 \mathrm{~Hz}$ ). By definition, elastic solids (approximated by the calcite plates) do not exhibit force relaxation; by contrast, viscoelastic materials such as the ligaments do exhibit force relaxation (Wainwright et al. 1976). Thus the degree of relaxation should reflect changes in the ligamental contribution to the structural response. An experimental peak force of $15 \mathrm{~N}$ was chosen because it is much less than the break- ing force of these urchins. (A force of $15 \mathrm{~N}$ is only $4 \%$ of the mean breaking force of intact $S$. droebachiensis of the same mean size $(n=59$, mean weight $=69.4 \pm 1.8 \mathrm{~g}$, mean breaking force $=362 \pm 13 \mathrm{~N}$ ) that were collected at the same time from the same site as the urchins used in the 13-week experiment described above.)

To determine the relationship between size and sutural looseness, $S$. droebachiensis were collected during June from three intertidal sites (Giant Stairs, Ocean Point and Chamberlain, Maine), one subtidal kelp site (Jericho Island, Maine), and two subtidal urchin barren sites (Jericho Island and East Bailey Island, Maine). At each site, between 32 and 59 urchins were collected (total $=285$ urchins), ranging in size from $23 \mathrm{~mm}$ to $84 \mathrm{~mm}$ in diameter. Test diameters were measured $( \pm 0.7 \mathrm{~mm})$ three times for each urchin. Urchins were then bleached, airdried, and categorized as either disarticulated or intact.

To compare sutural looseness with growth, the size-specific growth rate was calculated using a Tanaka ${ }^{1}$ function fitted by Russell et al. (1998). They present parameters of the Tanaka function for measurements of jaw height of $S$. droebachiensis urchins from their tide pools 2-7 in Maine; they also present a measured allometric power function relating jaw height to urchin diameter. As Russell et al. (1998) used those two relationships to determine a function that relates diameter to age, the authors also followed this method. The derivative of that function with respect to time was used to obtain a diametrical growth rate as a function of age. A parametric plot of these two functions of age produced a size distribution of growth rates to compare with the size distribution of looseness.

\section{(b) Sutural looseness and calcite accretion in Strongylocentrotus franciscanus}

To examine skeletal growth associated with feeding-induced weight gain, $25 \mathrm{~S}$. franciscanus, collected subtidally near Bodega Head, California, were injected through the peristomial membrane with $0.2 \mathrm{ml}$ each of $2 \mathrm{~g}$ per $100 \mathrm{ml}(40 \mathrm{mM})$ tetracyclineHCL. The urchins were assigned at random to either an unfed group or a group fed mussel flesh ad libitum. Urchins were kept in a 3001 recirculating seawater aquarium at $10{ }^{\circ} \mathrm{C}$ under natural lighting conditions for two and a half weeks at the end of May. Individuals were weighed at the beginning and end of the period. Afterwards, all urchins were sacrificed, bleached and areas of calcite addition were visualized using a multiband (254$366 \mathrm{~nm}$ ) UV light.

\section{(c) Calcium ions and ligament properties in Lytechinus pictus}

We tested whether sutural ligaments share, in common with mutable collagenous tissues (MCT), the property that they soften in solutions lacking calcium ions. To facilitate this, the breaking strength was determined of $54 \mathrm{~L}$. pictus urchins that were assigned at random to one of three treatments: (i) soaked for $24 \mathrm{~h}$ in natural seawater, (ii) soaked for $24 \mathrm{~h}$ in divalent cation-free seawater (DCF) and (iii) bleached. The breaking strength was determined using the method described above for force relaxation except that skeletons were compressed until they broke.

\section{RESULTS}

\section{(a) Growth and sutural changes in}

\section{S. droebachiensis}

The initial weights in the fed and the unfed $S$. droebachiensis were not significantly different for either the 13-week 
(a)

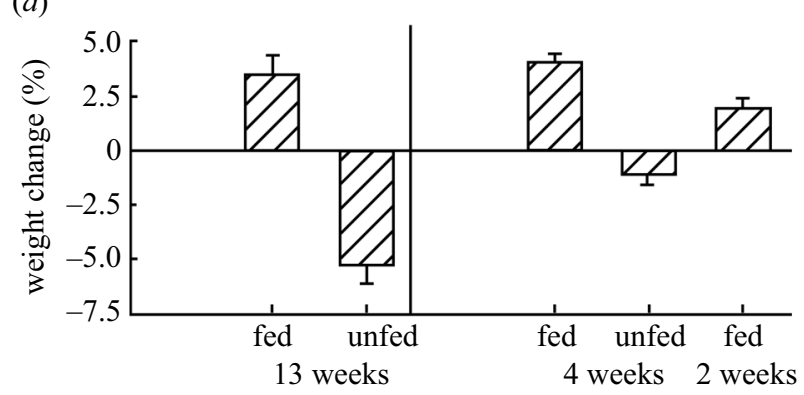

(1)

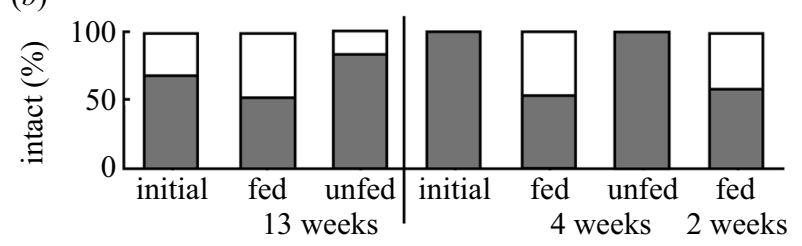

(c)

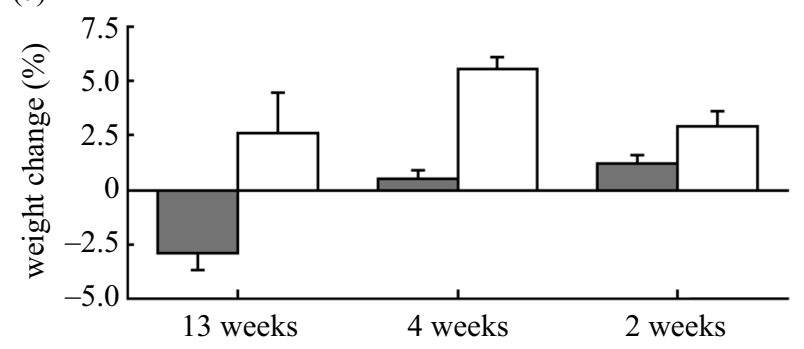

Figure 1. Growth and sutural looseness in S. droebachiensis. Fed urchins gained weight and unfed urchins lost weight $(a)$. Feeding tended to loosen sutures $(b)$ with the percentage remaining intact when bleached (grey bars) decreasing in all fed groups. Weight gains were highest in loose-sutured urchins $(c)$. Error bars indicate one standard error.

experiment $(p=0.52, U$-test; fed: $n=25$, mean $=68.7 \pm 2.4 \mathrm{~g}$; unfed: $n=28$, mean $=69.3 \pm 3.1 \mathrm{~g})$ or the four- and two-week experiment $(p=0.57$, Kruskal-Wallis test; fed: $n=38$, mean $=69.1 \pm 2.9 \mathrm{~g}$; unfed: $n=22$, mean $=69.8 \pm 3.6 \mathrm{~g}$; unfed-then-fed: $n=12$, mean $=74.7 \pm 5.2 \mathrm{~g})$.

During the 13-week period, weight change differed between fed and unfed $S$. droebachiensis $(p=0.0001$, $U$-test), with fed urchins gaining $2.2 \pm 0.7 \mathrm{~g}(p=0.005$, paired $t$-test) and unfed urchins losing $3.7 \pm 0.4 \mathrm{~g}$ $(p<0.0001$, paired $t$-test; figure $1 a)$. Fed urchins were more likely to disarticulate under their own weight after bleaching than were unfed urchins $\left(p=0.02, \chi^{2}\right.$-test; figure $1 b$ ). The weight gain (figure $1 c$ ) of urchins that disarticulated was higher than the weight gain of those that remained intact $(p=0.008, U$-test; 17 disarticulated with a mean weight change of $1.9 \pm 1.1 \mathrm{~g}$ and 36 remained intact with a mean weight change of $-2.2 \pm 0.5 \mathrm{~g}$ ). Both disarticulation and the feeding regime were predictive of weight change (multiple regression of weight change versus disarticulation and feeding regime: $r^{2}=0.57$; effect tests: disarticulation, $p<0.01$; feeding regime $p<0.0001)$.

During the four-week period, weight change differed between fed and unfed urchins $(p=0.0001, U$-test $)$ with fed urchins gaining $2.5 \pm 0.3 \mathrm{~g}(p=0.0001$, paired $t$-test $)$ and unfed urchins losing $0.7 \pm 0.1 \mathrm{~g}(p=0.0001$, paired $t$-test; figure $1 a$ ). Fed urchins were more likely to disarticulate under their own weight after bleaching than were either unfed urchins $\left(p<0.0001, \chi^{2}\right.$-test, figure $\left.1 b\right)$ or the initial controls (19 initial urchins, $p<0.0001, \chi^{2}$-test). No unfed urchins and no initial controls disarticulated.

For both the four- and the two-week experiments, the weight gain (figure $1 c$ ) of urchins that disarticulated was higher than the weight gain of those that remained intact (four weeks: $p=0.0001, U$-test; 20 disarticulated with a mean weight change of $3.2 \pm 0.3 \mathrm{~g}$ and 40 remained intact with a mean weight change of $0.4 \pm 0.3 \mathrm{~g}$; two weeks: $p=0.06, U$-test; five disarticulated with a mean weight change of $1.9 \pm 0.5 \mathrm{~g}$ ) and seven remained intact with a mean weight change of $0.9 \pm 0.3 \mathrm{~g}$. At four weeks, both disarticulation and the feeding regime were predictive of weight change (multiple regression of weight versus disarticulation and feeding regime: $r^{2}=0.64$; effects tests: disarticulation, $p<0.001$; feeding regime $p<0.0001$ ).

There were differences in force relaxation after $180 \mathrm{~s}$ among the four treatments (figure $2 b ; p=0.03$, ANOVA). The only significant, pairwise comparison was that, at four weeks, fed urchins force-relaxed more after $180 \mathrm{~s}$ (mean fraction of peak force $=0.72 \pm 0.018$ ) than did unfed urchins (mean fraction of peak force $=0.81 \pm 0.016$; $a$ posteriori $p=0.003$, Fisher's protected least-significant difference (PLSD)). All other pairwise comparisons of means were not significantly different (all other a posteriori $p>0.19$, Fisher's PLSD). Skeletons that disarticulated came from urchins that underwent greater force relaxation (figure $2 c$, mean fraction of peak force $=0.71 \pm 0.017$, $n=25$ ) than those that remained intact (mean fraction of peak force $=0.78 \pm 0.013, n=54 ; p=0.0005, U$-test).

The size distribution of looseness in field populations (figure 3) resembled that of the size distribution of growth rates reported by Russell et al. (1998). Spearman's rank correlation statistics, calculated only for size categories collected from all six locations, indicated that smaller urchins were more likely to disarticulate $(p=0.002$; $\rho=-0.5)$.

\section{(b) Sutural looseness and calcite accretion in $\mathbf{S}$. franciscanus}

Growth statistics for the tetracycline-marked $S$. franciscanus were as follows. The initial weights in the fed and the unfed groups were not significantly different $(p=0.3$, $U$-test; fed: $n=15$, mean $=299 \pm 27 \mathrm{~g}$; unfed: $n=10$, mean $=370 \pm 5 \mathrm{~g}$ ). During the two-and-a-half-week period, the fed urchins gained an average of $6.5 \pm 0.9 \mathrm{~g}$ (paired $t$-test, $p<0.0001$ ). In contrast, the unfed urchins lost an average of $2.7 \pm 1.3 \mathrm{~g}$, which was a nearly significant loss (paired $t$-test, $p=0.07$ ). These weight changes in the fed and unfed groups were significantly different from each other ( $U$-test: $p<0.0001)$. The weight changes represented a gain of $2.5 \pm 0.4 \%$ and a loss of $0.6 \pm 0.2 \%$, respectively. When bleached, all urchin skeletons in the fed group disarticulated at plate edges under their own weight, whereas all skeletons from the unfed group remained intact. All skeletons in the fed group glowed at the plate margins when viewed under UV light, whereas those in the unfed group did not (figure 4). Thus, fed urchins were incorporating calcite whereas unfed urchins were not. 
(a)

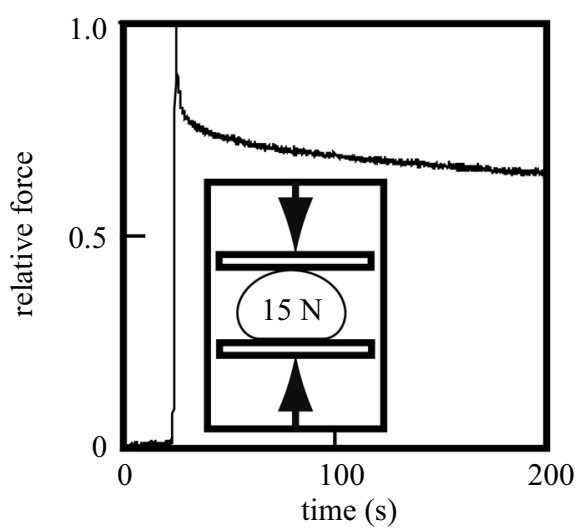

(b)

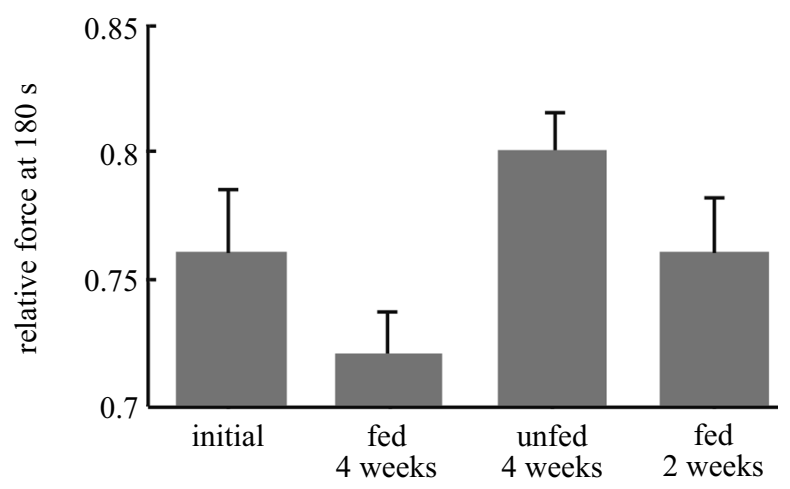

(c)

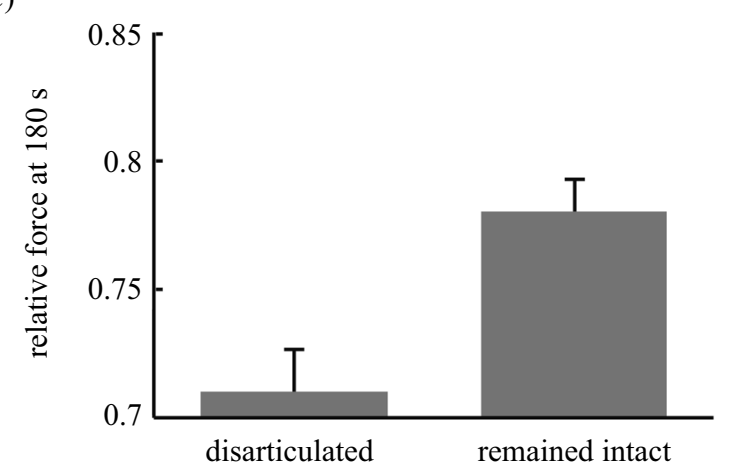

Figure 2. Force relaxation and sutural looseness in $S$. droebachiensis. Force relaxation was measured on whole urchins $(a)$. The more an urchin force-relaxes the lower the relative force at $180 \mathrm{~s}$. Fed urchin skeletons force-relaxed more than unfed urchins $(b)$ and loose-sutured urchins force-relaxed more than did tight-sutured urchins (c). Thus, the material properties of an urchin's skeleton are changed by feeding and are associated with weight gain. Error bars indicate one standard error.

\section{(c) Calcium ions and ligament properties in \\ L. pictus}

The breaking strength of $L$. pictus differed significantly between all treatments (overall ANOVA, $n=18$ urchins per treatment, d.f. $=2,52, p<0.0001$ that mean breaking strength was the same for all treatments; a posteriori Fisher PLSD, each pairwise $p<0.05)$. The breaking strength was greatest for urchins soaked for $24 \mathrm{~h}$ in natural seawater $($ mean $=45.4 \pm 3.4 \mathrm{~N}$ ), was reduced by soaking for $24 \mathrm{~h}$ in DCF (mean $=26.3 \pm 1.5 \mathrm{~N}$ ) and was least for the bleached urchin skeletons (mean $=6.2 \pm 0.25 \mathrm{~N}$ ). Since the bleached skeletons broke at the lowest force, sutural

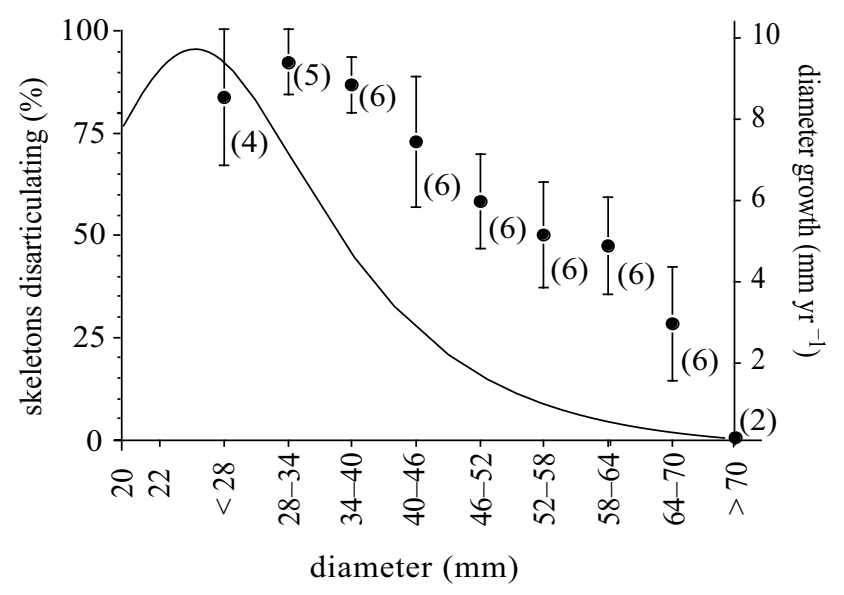

Figure 3. Diametrical growth rate (solid line, right axis) and percentage of skeletons disarticulating (points with s.e. bars, left axis) plotted as functions of diameter in S. droebachiensis. The diametrical growth rate shows a similar pattern of change with size as does the sutural looseness. Size-specific looseness was quantified by the percentage of bleached urchin skeletons in each size class that disarticulated. The disarticulation assay was done on 285 urchins sampled from six field sites in Maine. Numbers of locations represented in each size class are shown in brackets beside s.e. bars. Sizespecific growth rates were estimated from Tanaka functions for the same species using data from Russell et al. (1998).

ligaments were responsible for the higher breaking forces in the other treatments.

\section{DISCUSSION}

The growth we quantified is associated with longer-term size increase, as can be seen in the associated deposition of calcite (figure 4). The growth rates observed in the current experiment can be compared with field growth rates. The fastest growing urchins, those with loose sutures, had growth rates of $5.5 \%$ and $2.9 \%$ by weight over four and two weeks, respectively (figure $1 c$ ). If sustained, these rates would translate into increases of $26 \%$ and $28 \%$ by diameter per year. ${ }^{2}$ But field populations in the same size range (43-71 mm) have lower yearly diametrical growth rates of between $10 \%$ and $1 \%$, respectively (figure 3 ). These discrepancies between field and laboratory growth rates suggest that these high rates are unsustainable for urchins of this size. Indeed, the growth rate in the fed group in the 13 -week experiment was $3.5 \%$ by weight per 13 weeks (or $5 \%$ by diameter per year), which is more consistent with rates seen in the field. Thus, urchins show an initially rapid weight increase in response to the availability of food, but sustained growth appears more limited.

Field growth rates are highly variable and, in particular, field populations of smaller urchins (10-20 mm diameter) can have higher, diametrical, growth rates of $40-100 \%$ (Russell et al. 1998). The rapid response to food seen in the experimental groups in this study is one mechanism by which such variability may be generated. Growth rates observed in the four- and two-week experiments indicate that even larger urchins can double or triple growth rates at least temporarily.

During the periods of growth observed in our experimental urchins, sutures loosened (figure 1). Such loosen- 


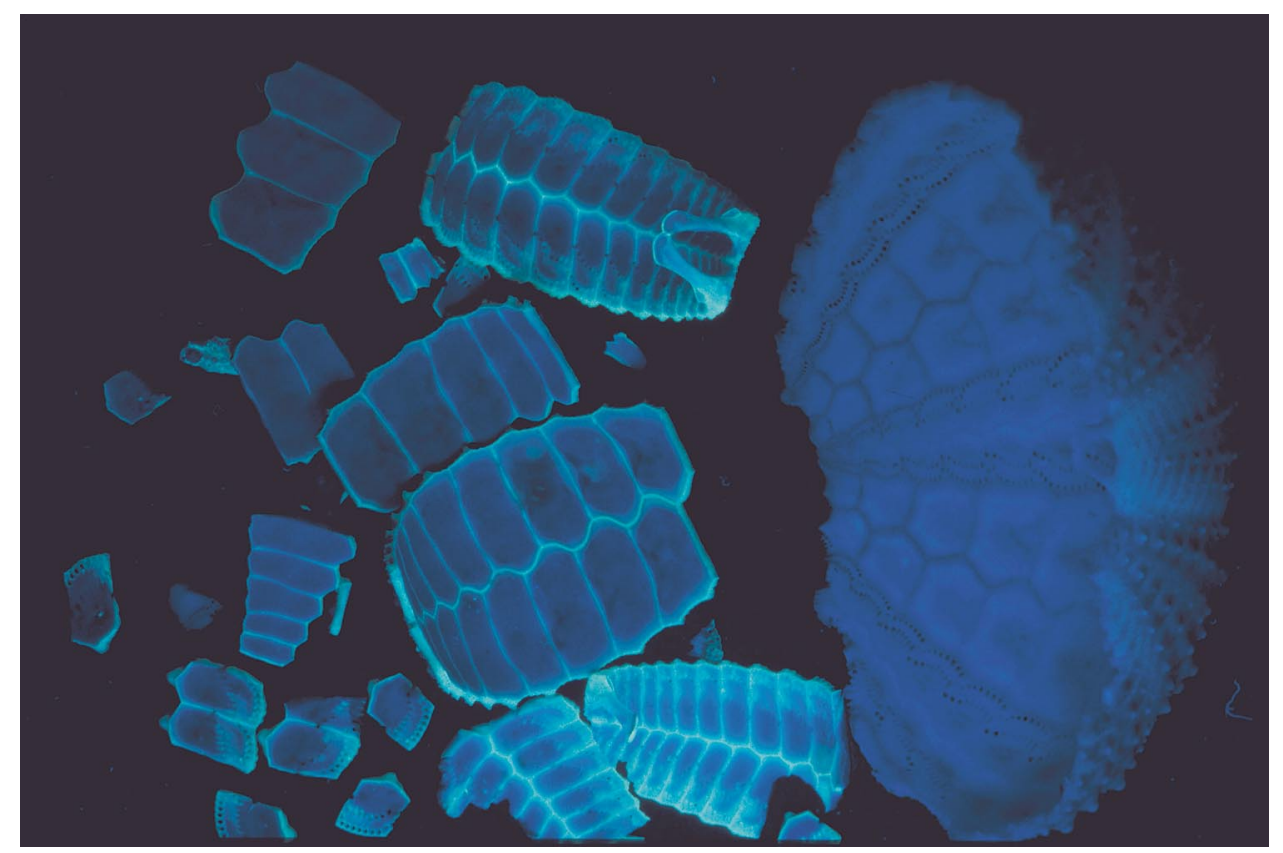

Figure 4. Bleached skeletons of $S$. franciscanus that had been injected with tetracycline label and were fed (left) and unfed (right) for two and a half weeks. Under UV illumination, skeletons of unfed urchins showed no tetracycline-marked lines indicating no addition of calcite whereas fed urchins showed such lines indicating addition of calcite at the plate edges. Fed urchins also disarticulated at plate margins under their own weight, whereas unfed urchins had to be broken to produce the photograph shown (note breaks across plates rather than along sutures).

ing is also seen in field populations where the proportion of loose-sutured urchins in a given size class is related to the growth rate typical of that size class (figure 3). Loose sutures allow the flexibility that is crucial to a mathematical model used to calculate urchin-like shapes from patterns of forces acting on the skeleton (Ellers 1993). Because loose sutures are bound together by sutural ligaments, the ligaments may play a role in growth.

Sutural ligaments presumably lengthen when sutural gaps widen and shorten when sutural gaps narrow. During growth, sutural collagenous ligaments may soften and elongate by creeping, under the influence of coelomic pressure. Coelomic pressure fluctuates above and below zero (Ellers \& Telford 1992) and its magnitude is independent of urchin growth. If ligaments creep when pressure is positive and bend or shorten when pressure is negative, a net extension of the sutural ligaments could occur mechanically. Perhaps the material properties of sutural ligaments change such that creep is increased during growth.

Tissues that creep more can be expected to force-relax more and greater force relaxation was seen in growing, loose-sutured urchins (figure $2 b, c$ ). Loose-sutured urchins are those that, when bleached, would disarticulate under their own weight. Thus, in loose-sutured urchins, force relaxation reflects the material properties of the ligaments, the applied $15 \mathrm{~N}$ force being much higher than the force required to disarticulate the plates in the absence of ligaments (Ellers et al. 1998). For urchins with tighter sutures, force relaxation may be due to less soft ligaments and/or to some interactions between adjacent calcite projections at the sutures. Notwithstanding this, the skeletal plateligament composite force-relaxes more and thus presumably creeps more, in fed, growing urchins with loose sutures.
Growth-associated changes in ligamental material properties do occur in other echinoderm tissues. For example, the dental ligaments of sea urchins and sand dollars soften periodically (Ellers \& Telford 1996) allowing teeth to be advanced by dental promoter muscles. Material property changes not associated with growth can also occur, as in echinoderm MCTs. MCTs can change from stiff to compliant states within seconds or minutes and are thought to be under nervous control (Wilkie 1996). Two examples of such tissues are the ligaments at the base of sea urchin spines and the body wall of sea cucumbers. Unlike vertebrate collagenous tissues, MCTs soften when exposed to a lowered calcium concentration. Dental ligaments (Ellers \& Telford 1996) and sutural ligaments ( $L$. pictus in this paper) also soften in Ca-free solutions. Sea urchin spine and sutural ligaments contain a novel protein, fibrosurfin, which may be unique to echinoderms (Cluzel et al. 2001). Because fibrosurfin contains epidermal growth factor-like domains, it might be responsible for some of the Ca-dependence in mechanical properties of MCTs (but see Trotter \& Koob 1995). The molecular and Ca-dependency similarities between sutural and spine ligaments strengthen the speculation by Ellers \& Telford (1996) that the mutable properties of MCT may have had evolutionary origins in tissues that were mutable during growth.

This research was supported by a University of California Agricultural Research Station grant no. 5134-H to O.E., an Arthur Vining Davis grant, a Kenan grant and a Fletcher Family Fund grant to A.J. and a SURDNA foundation fellowship to M.M. The authors thank Malcolm Telford for joyous discussions and two anonymous reviewers for their helpful comments on the manuscript. 


\section{ENDNOTES}

${ }^{1}$ The Tanaka function given in eqn (1) in Russell et al. (1998) contains a misprint. For the correct function see eqn (2) of Ebert et al. (1999). Furthermore, the correct Tanaka function used with the parameters reported in Russell et al. (1998) must be multiplied by a conversion of 10 (to convert $\mathrm{cm}$ to $\mathrm{mm}$ ) to obtain the units for jaw height as shown in their fig. 5. Tanaka function parameters used were: $a=34.448$; $d=-0.1616 ; f=38.883 ; c=11.7 \mathrm{yr}$.

${ }^{2}$ Sample calculation: growth rate of $2.9 \%$ per two weeks by weight, if sustained, corresponds to a factor of $1.029^{26}=2.1$ times per year and, assuming isometry, that fractional weight change corresponds to a diameter change of $2.1\left({ }^{1 / 3}\right)=1.28$, or an increase of $28 \%$.

\section{REFERENCES}

Baron, C. J. 1991 The structural mechanics and morphogenesis of extant regular echinoids having rigid tests. $\mathrm{PhD}$ thesis, University of California, Berkeley.

Cluzel, C., Lethias, C., Humbert, F., Garrone, R. \& Exposito, J. Y. 2001 Characterization of fibrosurfin, an interfibrillar component of sea urchin catch connective tissues. f. Biol. Chem. 276, 18 108-18 114.

Constable, A. J. 1993 The role of sutures in shrinking of the test in Heliocidaris erythrogramma (Echinoidea: Echinometridae). Mar. Biol. 117, 423-430.

Dafni, J. 1986 A biomechanical model for the morphogenesis of regular echinoid tests. Paleobiology 12, 143-160.

Deutler, F. 1926 Über die Wachstum des Seeigelskeletts. Zool. fb. Abt. Anat. Ontog. Tier. 48, 119-200.

Ebert, T. A. 1967 Negative growth and longevity in the purple sea-urchin Strongylocentrotus purpuratus (Stimpson). Science WA 157, 557-558.

Ebert, T. A., Dixon, J. D., Schroeter, S. C., Kalvass, P. E., Richmond, N. T., Bradbury, W. A. \& Woodby, D. A. 1999 Growth and mortality of red sea urchins Strongylocentrotus franciscanus across a latitudinal gradient. Mar. Ecol. Prog. Ser. 190, 189-209.

Eble, G. J. 2001 Developmental morphospaces and evolution. In Evolutionary dynamics - exploring the interplay of selection, neutrality, accident, and function (ed. J. P. Crutchfield \& P. Schuster), pp. 35-65. Oxford University Press.

Ellers, O. 1993 A mechanical model of growth in regular sea urchins: predictions of shape and a developmental morphospace. Proc. R. Soc. Lond. B 254, 123-129.

Ellers, O. \& Telford, M. 1992 Causes and consequences of fluctuating coelomic pressure in sea urchins. Biol. Bull. 182, 424-434.

Ellers, O. \& Telford, M. 1996 Advancement mechanics of growing teeth in sand dollars (Echinodermata, Echinoidea): a role for mutable collagenous tissue. Proc. R. Soc. Lond. B 263, 39-44.

Ellers, O., Johnson, A. S. \& Moberg, P. 1998 Sutural strengthening of urchin skeletons by collagenous sutural ligaments. Biol. Bull. 195, 136-144.

Foote, M. 1997 The evolution of morphological diversity. A. Rev. Ecol. Syst. 28, 129-152.

Levitan, D. R. 1991 Skeletal changes in the test and jaws of the sea urchin Diadema antillarum in response to food limitation. Mar. Biol. 111, 431-435.

McGhee, G. R. 1998 Theoretical morphology. New York: Columbia University Press.

Russell, M. P., Ebert, T. A. \& Petraitis, P. S. 1998 Field estimates of growth and mortality of the green sea urchin, Strongylocentrotus droebachiensis. Ophelia 48, 137-153.

Stone, J. R. 1997 The spirit of D'Arcy Thompson dwells in empirical morphospace. Math. Biosci. 142, 13-30.

Thompson, D. A. W. 1917 On growth and form. London: Cambridge University Press.

Trotter, J. A. \& Koob, T. J. 1995 Evidence that calciumdependent cellular processes are involved in the stiffening response of holothurian dermis and that dermal cells contain an organic stiffening factor. F. Exp. Biol. 198, 1951-1961.

Wainwright, S. A., Biggs, W. D., Currey, J. D. \& Gosline, J. M. 1976 Mechanical design in organisms. Princeton University Press.

Wilkie, I. C. 1996 Mutable collagenous tissues: extracellular matrix as mechano-effector. In Echinoderm studies 5 (ed. M. Jangoux \& J. M. Lawrence), pp. 61-102. Rotterdam: Balkema. 